\title{
Coupling numerical model of hydraulic fracturing seepage in soft coal based on elastoplastic damage
}

\author{
LI Liangwei ${ }^{1,2, *}$ \\ ${ }^{1}$ Chongqing Research Institute, China Coal Technology and Engineering Group, Chongqing 400037, China \\ ${ }^{2}$ State Key Laboratory of The Gas Disaster Detecting, Preventing and Emergency Controlling, Chongqing 400037, China
}

\begin{abstract}
In order to guide the field application of hydraulic fracturing of soft coal in coal mine, based on the elastic-plastic damage theory, the coupling numerical model of soft coal hydraulic fracturing seepage was studied. The porosity strain relationship equation, permeability strain relationship equation, the relationship between permeability and volume plastic tensile strain and volume plastic shear strain of coal and rock mass are derived, and the plastic correction equation and softening parameters are defined. The stress coupling equation and yield criterion are programmed and embedded into the finite difference software FLAC3D for numerical solution. The numerical simulation shows that the numerical calculation model of soft coal hydraulic fracturing conforms to the actual law, and the field fracturing radius investigation experiment is consistent with the numerical simulation results.
\end{abstract}

\section{Preface}

The application of hydraulic fracturing technology in coal mine provides a strong support for gas disaster prevention and coal mining, while the research on seepage characteristics and seepage stress coupling of coal and rock mass provides theoretical support for hydraulic fracturing of coal and rock mass. For example, in the early stage, brace [1] proved that the internal cracks and macro cracks in the material are highly correlated with the seepage characteristics. Li. S. P [2] found that the permeability under stress and strain is more sensitive than that under axial seepage pressure and deformation. W. L. Zhu and t. F. Wong [3] found that the shear dilatancy brittle fracture and the cataclastic zone presented a process of transformation and permeability reduction successively. J. A. Wang and $\mathrm{H}$. D. Park [4] found that the influence of confining pressure on permeability is greater than that of axial pressure. Hu Dawei [5] found that the internal damage strain cannot be recovered after axial stress loading and unloading. Wang Guangrong [6] and others found that the surface damage degree of coal sample permeability test is higher. The experimental results of Yin Guangzhi [7] and others show that the seepage presents obvious lag effect due to the gas analysis process.

Because there are many low permeability soft coal in China, many scholars have also carried out the coupling study of soft coal seepage. Zhao Zhigen et al. [8] studied the difference in strength between soft coal and hard coal, and the stress-strain curve is also very different. Weijian $\mathrm{Yu}$ et al. [9] experiments show that internal factors (heterogeneity) are also one of the important factors causing brittle ductile transition of soft coal. Zhang
Tianjun et al. [10-11] established the damage evolution model of soft coal under loading, which reflects the inelastic mechanical effect of soft coal in meso damage. $\mathrm{Gu}$ Yifan [12] studied the pore structure characteristics of soft and hard coal.

In order to analyze the effect of water injection on the effect of soft coal seam, Zhou Peng [13] experiment shows that after water injection, the plastic properties of soft coal become smaller and the ductility is enhanced. Jia Bing, Wei Jianping et al. [14] test shows that the acoustic emission value of soft coal is small and the overall degree of kurtosis is larger than that of hard coal. Y. Fuji [15] pointed out through experiments that the circumferential strain can be used as an important index for damage judgment. W. Yang [16] demonstrated that soft rock is suitable for classical unified rheological model based on Rheological Experiment of soft coal. Xu Mangui et al. [17] studied the influence of pore structure characteristics of soft coal on gas occurrence and migration characteristics of coal body by using fractal theory. Ma Yankun [18] concluded that with the injection of high-pressure water, the strength of coal decreases and the plasticity increases.

To sum up, a lot of microscopic research on coal rock mass and soft coal is carried out, but it is still lack of combination with engineering application. In order to guide the field with theory, the numerical algorithm based on soft coal damage is deduced and combined with numerical simulation software to provide a new evaluation mode for hydraulic fracturing and permeability increase of soft coal seam.

* Corresponding author: sccqxu1@foxmail.com 


\section{Numerical solution based on FLAC3D model}

\subsection{Solving model and boundary conditions}

The seepage coupling equation and failure criterion are programmed and embedded into the finite difference software FLAC3D for numerical solution.

As shown in Fig. 1, a $1 / 2$ model of $200 \mathrm{~m}(\mathrm{x}) \times 200$ $\mathrm{m}(\mathrm{y}) \times 112 \mathrm{~m}(\mathrm{z})$ is established according to the formation parameters, and the grid is divided into 6270 nodes and 55200 units.

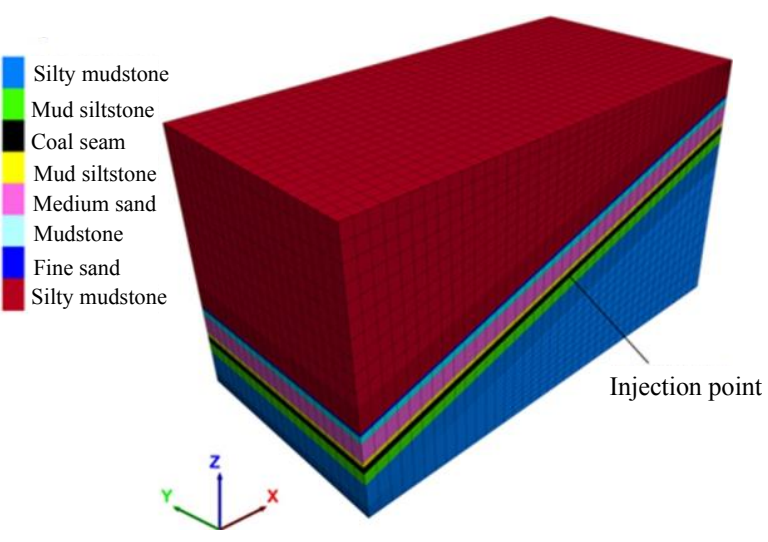

Fig. 1. Fracturing borehole sealing diagram.

Set $12 \mathrm{MPa}$ of overlying rock mass of multi-layer roof and set $1 \mathrm{MPa}$ initial pore pressure in coal seam. The critical value of plastic tensile stress is $1 \mathrm{e}^{-4}$ when the tensile strength of coal and rock mass is reduced to 0 . The relationship between setting, and volumetric shear strain and the relationship between setting, and volumetric shear strain are shown in Table 1.

Table 1. The relationship between $w_{c}, w_{\psi}$.

\begin{tabular}{|c|c|c|c|}
\hline$\varepsilon_{V}^{s p} / \mathbf{1 0}^{-4}$ & $\boldsymbol{w}_{\boldsymbol{c}}$ & $w_{\phi} /^{\circ}$ & $w_{\psi} /{ }^{\circ}$ \\
\hline 0 & 1.0 & 0.0 & 0.0 \\
\hline 0.05 & 0.50 & 3.0 & 4.0 \\
\hline 0.1 & 0.50 & 3.0 & 3.0 \\
\hline 1.0 & 1.00 & 0.0 & 0.0 \\
\hline
\end{tabular}

\subsection{Parameter law of hydraulic fission}

The fixed total pressure water inflow is $150 \mathrm{~m}^{3}$, and the fracture radius values are different under different flow rates. As shown in Fig. 2, when the flow rate increases from $1 \mathrm{~L} / \mathrm{s}$ to $2 \mathrm{~L} / \mathrm{s}$, the fracture radius changes greatly, and when the flow rate continues to increase, the fracture radius tends to decrease slightly. Because the total time of small flow rate is long, the filtration loss is large, the fracture radius is small. In the case of large flow rate, the fluid kinetic energy aggravates the coal fracture degree, and the fracture radius decreases instead of increasing.

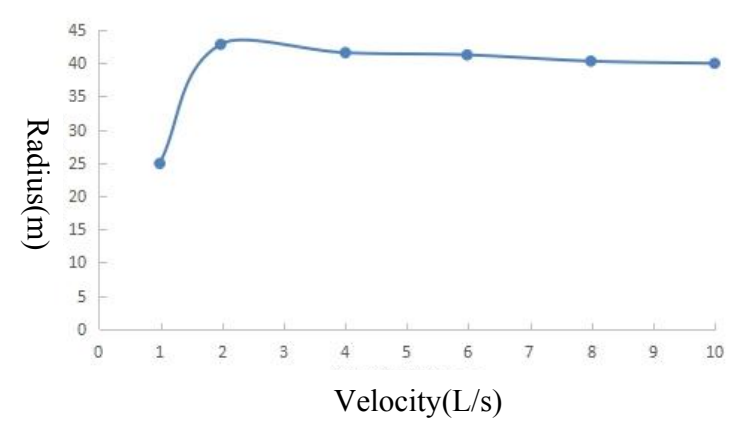

Fig. 2. Influence of water injection rate on fracture radius.

Fig. 3 shows the influence of different injection time on fracture radius when the flow rate is $3 \mathrm{~L} / \mathrm{s}$. From the initial condition to $1 \mathrm{~h}$, the fracturing radius changes rapidly when the water inflow is initially filled with the fractured coal near the borehole. Then, due to the existence of internal water pressure and resistance, the fracture radius increases slowly and tends to be linear and stable.

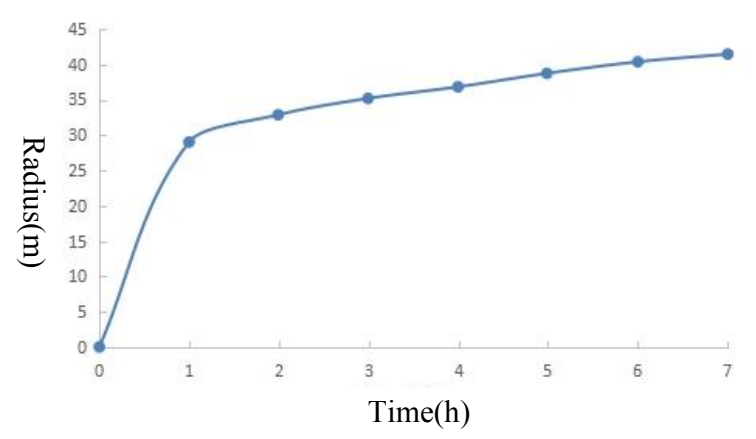

Fig. 3. Influence of injection time on fracture radius.

\subsection{Analysis of simulation results}

Fig. 4 and Fig. 5 show the front view and section nephogram of porosity after $3 \mathrm{~L} / \mathrm{s}$ flow and $150 \mathrm{~m}^{3}$ total water inflow respectively. It can be seen that the fracture zone is formed within the fracturing range, and the fracture radius in strike and dip is approximately equal. Porosity is not evenly distributed in the fracture radius, but forms a high to low distribution from the middle to the edge. At the same time, it can characterize the permeability distribution of coal.

Fig. 6 and Fig. 7 show the nephogram of volume plastic tensile and shear strain respectively. During fracturing, the coal body suffered shear and tensile failure at the same time. The development of shear failure in the roof and floor shows the distribution rule of high top and low bottom, which is less affected by gravity, and has no obvious angle relationship with the principal stress, which conforms to the stress-strain relationship in soft coal fracturing. 


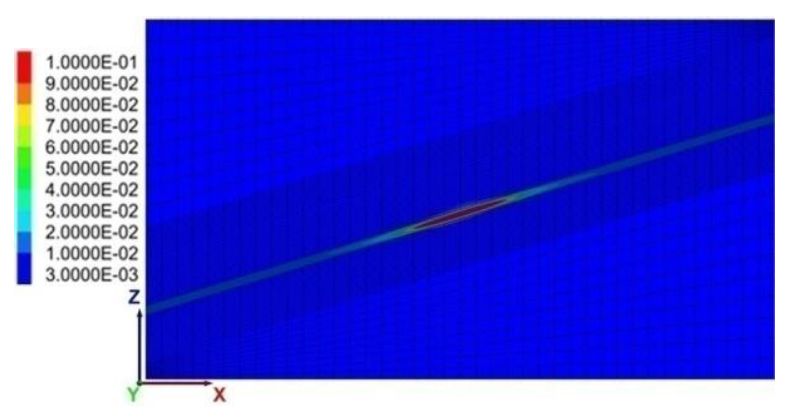

Fig. 4. Porosity contour of $X-Z$ plane.

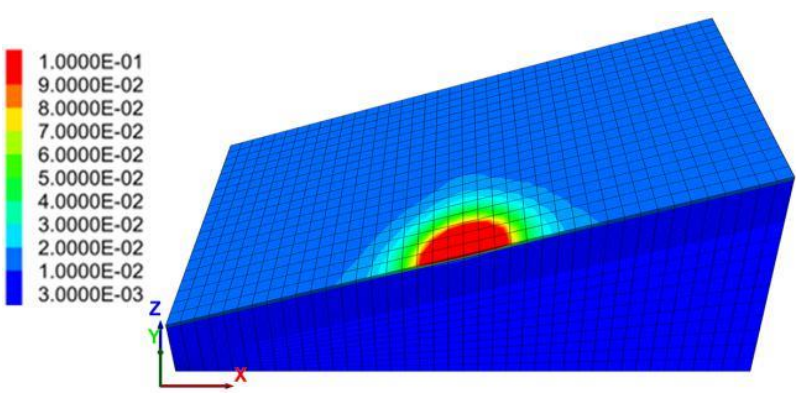

Fig. 5. Porosity contour along coal seam section.

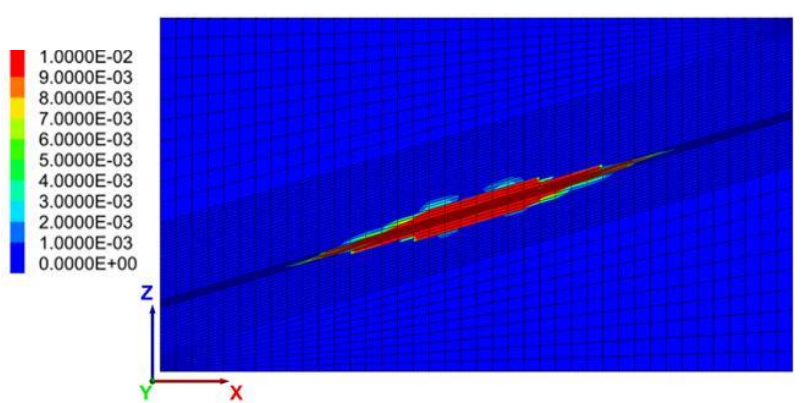

Fig. 6. Plastic tensile strain contour of $X-Z$ plane.

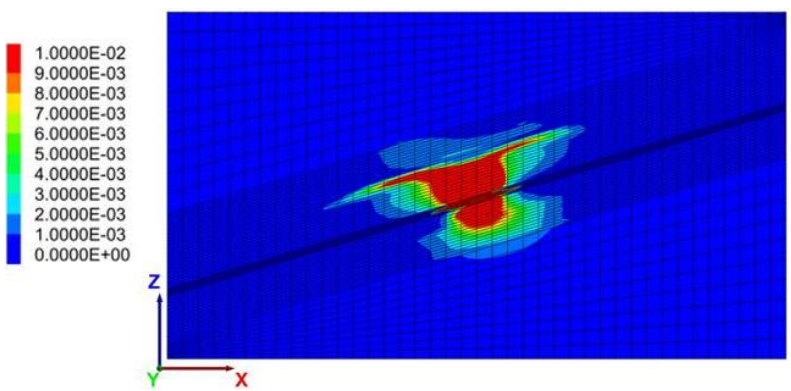

Fig.7. Plastic shear strain contour of $X-Z$ plane.

\subsection{Numerical analysis of hard coal and soft coal}

According to the model in Fig. 1, the traditional elastic deformation theory and fracture flow and expansion theory are used in the coal seam, and the same boundary conditions are used for simulation calculation. The difference between different flow rate and different injection time of the same flow rate is analyzed.

As shown in Fig. 8, when the flow rate increases from $1 \mathrm{~L} / \mathrm{s}$ to $2 \mathrm{~L} / \mathrm{s}$, the fracture radius of hard coal and soft coal changes greatly, but when the flow rate continues to increase, the fracture radius of hard coal increases slowly. This is due to the crack propagation of hard coal relative to soft coal, and the fracture conductivity makes the fracture length and range continue to expand. Similarly, as shown in Fig.9, when the flow rate of $3 \mathrm{~L} / \mathrm{s}$ is fixed and the total water inflow is $150 \mathrm{~m}^{3}$, the fracturing radius of hard coal increases approximately linearly after $1 \mathrm{~h}$, and the slope of soft coal is relatively small.

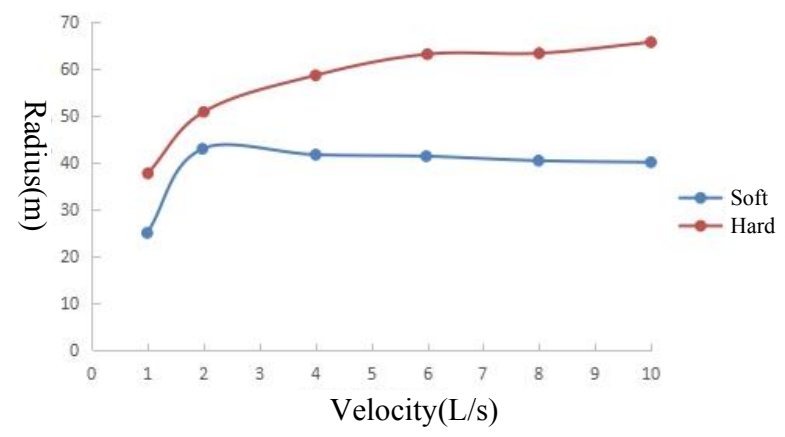

Fig.8. The difference rule of water injection rate to fracture radius of hard coal and soft coal.

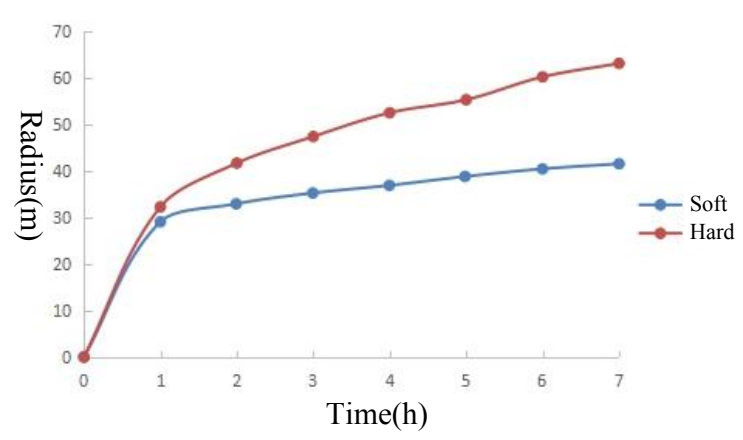

Fig.9. The difference rule of water injection time on fracture radius of hard coal and soft coa.

\section{Field verification}

In order to verify the correctness of the numerical model algorithm, field hydraulic fracturing was carried out in No.15 coal seam of a coal mine in Shanxi Province. The average flow rate was $6.4 \mathrm{~L} / \mathrm{s}$, and the total water inflow was $167 \mathrm{~m}^{3}$, lasting for $7.5 \mathrm{~h}$. In order to verify the fracturing radius, inspection holes were constructed from far to near around the fracturing hole to detect water seepage and coal powder infiltration. The field pressure control situation is shown in Fig. 10.

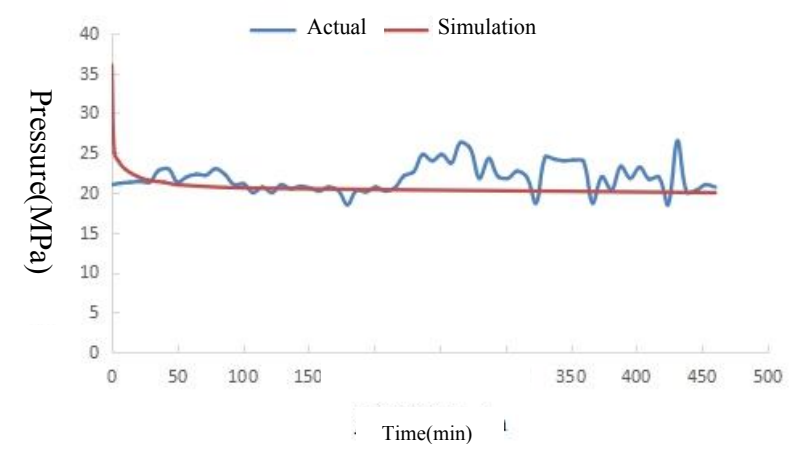

Fig. 10. Field pressure control.

Through drilling holes in strike and dip direction, the fracturing range is shown in Fig. 11. The fracture radius on strike is $60 \mathrm{~m}$ and that on dip is $40 \mathrm{~m}$. Due to the 
existence of natural fractures and hydraulic diffusion after hydraulic fracturing, the fracturing radius on strike and dip is deviated. The numerical calculation model, especially the model embedded in the numerical simulation software, can be used to predict the field hydraulic fracturing range of soft coal seam.

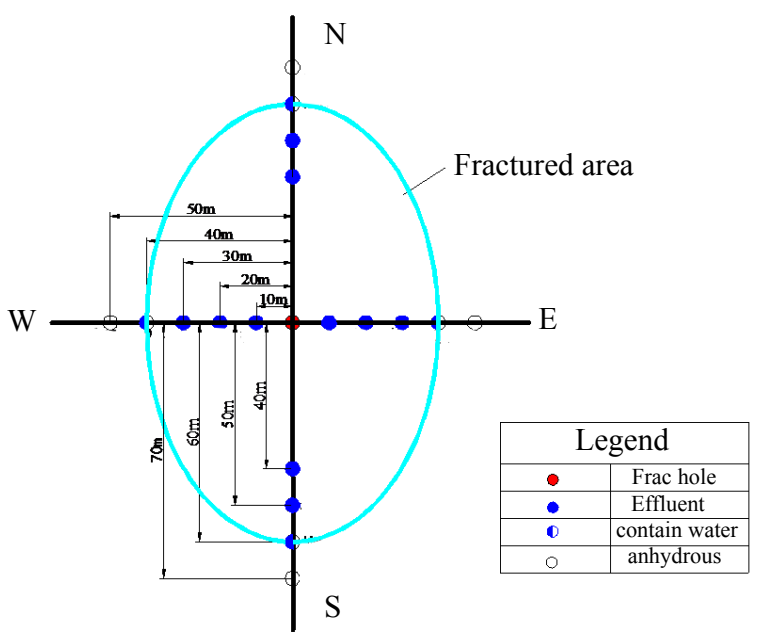

Fig.11. Investigation scope of hydraulic fracturing

\section{Conclusion}

(1) The dynamic evolution relationship of porosity with volume plastic tensile strain and volume plastic shear strain, the change relationship of coal and rock mass permeability with volume plastic tensile strain and volume plastic shear strain, and the change relationship of coal and rock mass permeability with volume plastic tensile strain and volume plastic shear strain, forming the stress seepage coupling model of hydraulic fracturing.

(2) Based on the incremental elastic theory, the plastic correction equation is formed, and the softening parameters defined by the increment equation of volume plastic tensile strain are used to form the failure criterion of soft coal.

(3) The numerical simulation shows that the numerical calculation model of soft coal fracturing accords with the actual law, and the investigation of fracturing radius by field experiment is consistent with the numerical simulation.

\section{Acknowledgments}

This paper was partially supported by "Thirteen FiveYear" National Major Special Projects (2016ZX05045004002, 2016ZX05067004001) and major scientific and technological innovation projects in Shandong Province(2019SDZY02). The authors also gratefully acknowledge the helpful comments and suggestions of the reviewers, which have improved the document.

\section{References}

1. W.F. brace. Journal of Petroleum Science and Engineering 23, 3343-3349 (1977)

2. S. Li. Tang. International Journal of Rock Mechanics and Mining Sciences 3-4, 1751-1758 (1997)

3. W. Zhu. Permeability evolution B2, 3027-3041 (1997)

4. J.a. Wang. Engineering Geology 3, 291-300 (2002)

5. D.W. Hu. Rock and Soil Mechanics 31, 2749-2754 (2010)

6. G.R. Wang. Journal of China Coal Society 37, 107$112(2012)$

7. G.Z. Yin. Chinese Journal of Rock Mechanics and Engineering 29, 170-175 (2010)

8. Z.G. Zhao, C.S. Li, C.J. Ying. Mine Construction Technology 37, 1-4 (2016)

9. W.J. Yu, G.S. Wu, B.F. An. Hindawi Geofluids 13, $1-15(2019)$

10. T.J. Zhang, X.G. Dong, H.Y. Pan. Coal Science and Technology 45, 88-94 (2017)

11. T.J. Zhang, H.L. Guo, C. Jing. Coal Science and Technology 2, 1-8 (2020)

12. Y.F. Gu, Z.F. Wang, L.L. Wei. Coal Science and Technology 44, 64-67 (2016)

13. P. Zhou, B. Zhang. Coal Science and Technology 45 , 103-108 (2017)

14. B. Jia, J.P. Wei, Z.H. Wen. Safety in Coal Mines 47, 200-203 (2016)

15. Y. Fuji, T. Kiyama, Y. Ishijima. International Journal of Rock Mechanics and Mining Sciences 36, 323-337 (1999)

16. W. Yang, Q. Zhao, S. Li. International Journal of Rock Mechanics and Mining Sciences 66, 169-176 (2014)

17. M.G. Xu, R. Meng, P. Wei. Mining Safety \& Environmental Protection 42, 22-26 (2015)

18. Y.K. Ma, E.Y. Wang, W.Q. Xu. Safety in Coal Mines 40, 74-77 (2009)

19. J.C. Wang, Z.H. Wang, D.Z. Kong. Journal of China Coal Society 40, 2243-2250 (2015)

20. Y. Wu, J. Liu, D. Elsworth. International Journal of Greenhouse Gas Control 4, 668-672 (2010)

21. Z.L. Zhang, W.Y. Xu, W. Wang. Chinese Journal of Rock Mechanics and Engineering 30, 3858-3862 (2011) 